\title{
PULMONARY ALVEOLAR MICROLITHIASIS: A CASE REPORT WITH EMPHASIS ON CLINICORADIOLOGICAL DISSOCIATION
}

\author{
Raghuram $U^{1}$, Md. Badusha², B. Anusha Bhargavi³, C. Ramanjula Reddy ${ }^{4}$, S. Satya Sri ${ }^{5}$
}

1 Junior Resident, Department of Pulmonology, ASRAMS, Eluru.

2Junior Resident, Department of Pulmonology, ASRAMS, Eluru.

$3 J u n i o r$ Resident, Department of Pulmonology, RMC, Kakinada.

4Senior Resident, Department of Pulmonology, ASRAMS, Eluru.

5 Professor \& HOD, Department of Pulmonology, ASRAMS, Eluru.

\section{ABSTRACT}

Pulmonary alveolar microlithiasis (PAM) is a rare disease characterised by the presence of small calculi in the alveolar space. The authors report a case of a 59-year-old woman with a 2-year history of dry cough. Physical examination was nil significant except for fine crackles at auscultation. Pulmonary function revealed a mild restrictive ventilatory defect and the chest radiograph demonstrated bilateral dense micronodular infiltrates giving diffuse sandstorm appearance. High-resolution CT scan revealed diffuse ground glass attenuation and septal thickening, more pronounced in mid and lower pulmonary regions, with calcifications along the interlobar septa and subpleural regions. A transbronchial lung biopsy confirmed the diagnosis of PAM.

\section{KEYWORDS}

PAM, Pulmonary Alveolar Microlithiasis, SLC34A2 Gene, Micronodular Infiltrates, Sandstorm Appearance.

HOW TO CITE THIS ARTICLE: Raghuram U, Badusha Md, Bhargavi BA, et al. Pulmonary alveolar microlithiasis: A case report with emphasis on clinicoradiological dissociation. J. Evolution Med. Dent. Sci. 2016;5(77):5768-5770, DOI: 10.14260/jemds/2016/1301

\section{INTRODUCTION}

Pulmonary alveolar microlithiasis (PAM) is a rare chronic disease characterised by multiple microscopic calculi within the alveoli and a paucity of symptoms in contrast to the imaging findings.[1-7] The disease is usually discovered incidentally during radiography of the chest for other reasons. Many patients are asymptomatic and the majority of patients either have normal or restrictive pulmonary function. The clinical course of the disease varies. While it remains static in some patients, it progresses into pulmonary fibrosis, respiratory failure and cor pulmonale in others. With the exception of lung transplantation, there is no known effective treatment for the disease. It is mostly accepted now that the disease has an autosomal recessive inheritance.[2,5,8] Recently, a few reports have described the role of mutation in the type IIb sodium-phosphate co-transporter gene (SLC34A2 gene) in the disease pathogenesis.[9,10] The authors present a case of symptomatic PAM in a 59-year-old woman, emphasising the role of high-resolution lung CT (HRCT) in the diagnosis of this unusual disease.

\section{CASE REPORT}

A 59-year-old female presented with a 2-year history of dry cough with no other significant symptomology. At physical examination, auscultation of the lungs revealed fine inspiratory crackles. Cardiac auscultation was normal, and no cyanosis or peripheral oedema was observed. There was no history of smoking or previous known pulmonary disease.

Financial or Other, Competing Interest: None.

Submission 19-08-2016, Peer Review 08-09-2016,

Acceptance 19-09-2016, Published 26-09-2016.

Corresponing Author:

Dr. Raghuram $U$,

\#10/154-D4-17,

Shanti Nagar, Gudivada-521301,

Andhra Pradesh.

E-mail: drraghuramu@gmail.com

DOI: $10.14260 /$ jemds/2016/1301
On routine blood examination, blood counts and serum chemistries were found to be normal. Arterial blood gas analysis and echocardiography showed no important abnormalities. USG abdomen was also normal.

Pulmonary function tests (PFT) showed a mild restrictive ventilatory defect. The sputum was negative for acid-alcohol resistant bacillus and human immunodeficiency virus testing was negative as well. The chest plain films revealed a diffuse symmetric dense bilateral micronodular pattern with middle to lower zone predilection giving a sandstorm appearance and black pleura sign could be made out (Figure 1). Based on this finding, HRCT scan was obtained, revealing diffuse ground glass attenuation with reticulations more pronounced in mid and lower pulmonary regions with thickening of the interlobar septa and calcifications of subpleural regions. Small subpleural cysts were also noticed (Figure 2). The patient underwent a fibreoptic bronchoscopy with bronchoalveolar lavage and transbronchial lung biopsy. The lavage fluid was negative for tubercle bacilli or fungi. Microliths were not found. Histology revealed round, concentrically laminated microliths in the alveoli associated with slightly thickened interstitial septa, consistent with the diagnosis of PAM. Her parents had expired and she had no siblings, so familial association could not be tested. She had two children and their chest plain X-ray films were normal.

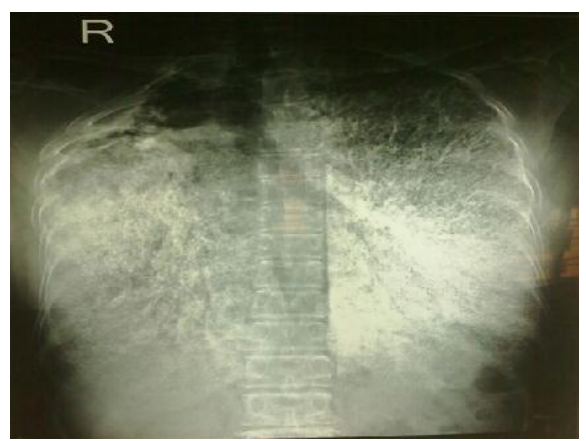

Fig. 1: Chest Radiograph in Anteroposterior view showing Diffuse Symmetric Lung Lesion with Confluence of Dense Micronodular Infiltrate. Note the, Predominance of the Lesions in the Paracardiac Regions of the Lungs 


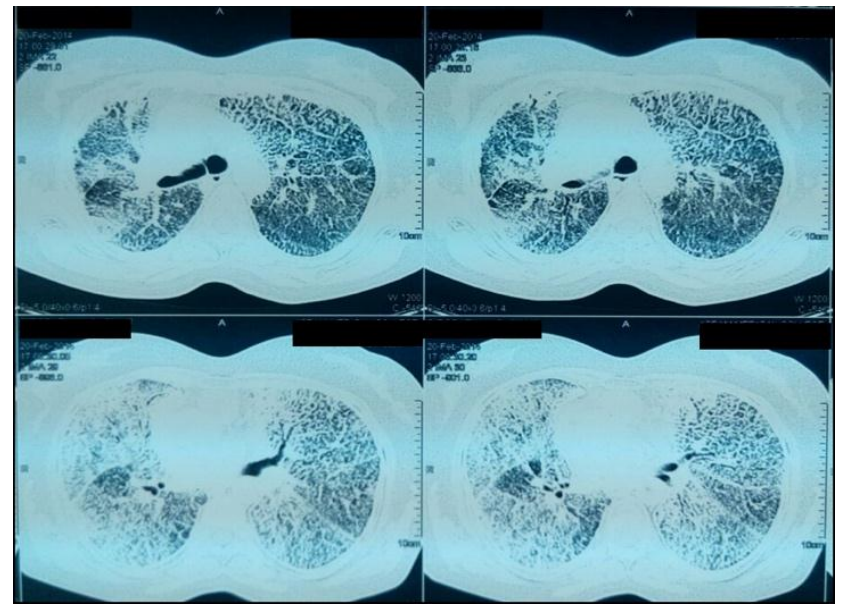

Fig. 2: High-resolution CT scan reveals Diffuse Groundglass Attenuation and Septal Thickening, more pronounced in lower Pulmonary Regions. Also, note Subpleural Cysts

\section{DISCUSSION}

PAM is a rare disease with poorly defined aetiology and pathogenesis, and is basically characterised by numerous small calculi (denominated calciferites, calcospherites or microliths) within air spaces in the absence of any known disorders in calcium metabolism. ${ }^{[1-7,11,12]}$ Patients may remain asymptomatic for many years and do usually become symptomatic between the third and fourth decades. ${ }^{[3,6,12]}$ At clinical presentation, patients usually demonstrate a lung disorder with restrictive pattern. ${ }^{[3,5-7,12]}$ as seen in our case. Adult patients commonly show progressive deterioration of the pulmonary function and death usually occurs in mid-life because of respiratory failure associated with cor pulmonale. ${ }^{[7,13,14]}$ Mean age at the time of diagnosis in the literature is 35 years and apparently there is no particular gender predilection. $[2,4,12]$ The disease presents a high incidence of familial occurrence (approximately one-third of the cases) suggesting an autosomal recessive inheritance pattern. $[2,5,8,12]$

Recently, a few reports have described the role of mutation in the type IIb sodium-phosphate co-transporter gene (SLC34A2 gene), which is involved in phosphate homeostasis in several organs, including the lung. ${ }^{[9,10]}$ SLC34A2 expression is observed in type 2 alveolar cells. These cells use phospholipids to produce surfactant and are also responsible for recycling and degrading the outdated surfactant. It is believed that the dysfunction in SLC34A2 may reduce the clearance of the phosphate released in this process, leading to the formation of microliths. For this reason, it is now accepted that this mutation is responsible for the pathologic changes seen in the pulmonary parenchyma in PAM.[10] Disodium etidronate, which inhibits microcrystal growth of hydroxyapatite and thus inhibits ectopic calcification, has been used to treat PAM. Although some reports show little or no benefit with the use of disodium etidronate.[11,12,14,15], a recent study regarding the long term results of the treatment in two cases, demonstrated an improvement at the patient's PFT and radiological changes.[16]

Besides that some authors demonstrated the usage of measuring the serum concentration of surfactant protein-A (SP-A) and surfactant protein-D (SP-D) in patients with PAM. Alveolar type 2 cells and Clara cells produce these two proteins in the lungs. The diffuse parenchyma fibrosis, consequent to
PAM, causes an increase in permeability, leading to an increase in the levels of these two proteins in the blood. Therefore, SP$A$ and SP-D measurement may be an alternative to monitor the progression and activity of the disease.[17] These exams were not performed in our patient. Nevertheless, no effective treatment for end-stage PAM currently exists, with the exception of lung transplantation.

Transplantation should be considered in cases where either severe respiratory failure or right heart failure are present. Patients who have undergone lung transplantation have showed an increase in right ventricular ejection fraction and regression of right ventricular hypertrophy.[14]

In the radiological diagnosis of PAM, chest radiographs usually reveal diffuse, bilateral areas of micronodular calcifications ("sandstorm") that predominate in the middle and lower lung areas.[2-7] The heart borders and the diaphragm are usually obliterated. Other typical finding includes a black pleural line, demonstrated as an area of increased translucence between the lung parenchyma and the ribs. $[2,4,5,7]$ The chest radiographs of our patient showed a diffuse symmetric lung lesion with dense micronodular aspect, similar to the pattern described in the literature.

The HRCT findings in patients with alveolar microlithiasis vary considerably.[2-7] Ground-glass opacities are the most common finding described in literature. $[2,4,5,7]$ This pattern occurs probably due to small calculi in the air space. Subpleural linear calcification, confluent and diffuse calcified nodules and dense consolidations are also a common finding. Calcifications along the bronchovascular bundles and at the central region of the bronchovascular tree can also be seen.[27] The CT scan confirms a predominance of symmetric calcifications along the heart borders and in the lower posterior portions of the lung.[2-4, 7] Small thin-walled subpleural cysts are described as well, and they are responsible for the "black pleura" sign seen in the chest $\mathrm{X}$ rays. $[2,4,5,11]$

Recently, it was described the unique characteristics of the mosaic pattern seen in alveolar microlithiasis, in which the interlobular septa are of calcium density is due to the deposition of calcospherites within the peripheral lobular parenchyma, adjacent to the septa. Some authors consider this pattern very specific and even pathognomonic of PAM on the HRCT scan, since this aspect has not been described in any other disease.[2,7] Clinicians should have in mind that some findings seen in PAM, such as nodular calcifications, can be found in other diseases like tuberculosis, metastatic osteosarcoma, amyloidosis and silicoproteinosis. Besides that, dense consolidations can also be found in metastatic pulmonary calcification, talcosis and amiodarone lung toxicity. In this way, associated CT findings and clinical features should always be correlated, since these diseases have different kinds of presentation and evolution.[18]

In conclusion, PAM is a rare disease that can affect young patients, with chronic and deteriorating evolution. Clinicians should be aware of its existence and the radiological features associated. The striking feature is lack of clinical findings despite significant radiological changes. The micronodular pattern seen in chest radiography can sometimes be misdiagnosed as miliary tuberculosis or other diseases that present with this pattern. In this way, HRCT should always be performed since it can reveal characteristic patterns of 
alveolar microlithiasis, reserving lung biopsy for atypical and inconclusive cases.

\section{REFERENCES}

1. Barbolini G, Rossi G, Bisetti A. Pulmonary alveolar microlithiasis. New England Journal of Medicine 2002;347(1):69-70.

2. Marchiori E, Gonçalves CM, Escuissato DL, et al. Pulmonary alveolar microlithiasis: high-resolution computed tomography findings in 10 patients. Jornal Brasileiro de Pneumologia 2007;33(5):552-7.

3. Hoshino H, Koba H, Inomata S, et al. Pulmonary alveolar microlithiasis: high-resolution CT and MR findings. Journal of Computer Assisted Tomography 1998;22(2): 245-8.

4. Cluzel P, Grenier P, Bernadac P, et al. Pulmonary alveolar microlithiasis: CT findings. Journal of Computer Assisted Tomography 1991;15(6):938-42.

5. Korn MA, Schurawitzki H, Klepetko W, et al. Pulmonary alveolar microlithiasis: findings on high-resolution CT. American Journal of Roentgenology 1992;158(5):981-2.

6. Helbich $\mathrm{TH}$, Wojnarovsky $\mathrm{C}$, Wunderbaldinger $\mathrm{P}$, et al. Pulmonary alveolar microlithiasis in children: radiographic and high-resolution CT findings. American Journal of Roentgenology 1997;168(1):63-5.

7. Gasparetto EL, Tazoniero P, Escuissatoet DL, et al. Pulmonary alveolar microlithiasis presenting with crazypaving pattern on high resolution CT. British Journal of Radiology 2004;77(923):974-6.

8. Castellana G, Gentile M, Castellana R, et al. Pulmonary alveolar microlithiasis: clinical features, evolution of the phenotype, and review of the literature. American Journal of Medical Genetics 2002;111(2):220-4.

9. Corut A, Senyigit A, Ugur SA, et al. Mutations in SLC34A2 cause pulmonary alveolar microlithiasis and are possibly associated with testicular microlithiasis. American Journal of Human Genetics 2006;79(4):650-6.
10. Huqun, Izumi $\mathrm{S}$, Miyazawa $\mathrm{H}$, et al. Mutations in the SLC34A2 gene are associated with pulmonary alveolar microlithiasis. American Journal of Respiratory and Critical Care Medicine 2007;175(3):263-8.

11. Jankovic N, Pavlov, Ivkosic A, et al. Pulmonary alveolar microlithiasis in childhood: clinical and radiological follow-up. Pediatric Pulmonology 2002;34(5):384-7.

12. Mariotta S, Ricci A, Papale M, et al. Pulmonary alveolar microlithiasis: report on 576 cases published in the literature. Sarcoidosis Vasculitis and Diffuse Lung Diseases 2004;21(3):173-81.

13. Tachibana T, Hagiwara K, Johkoh $\mathrm{T}$, et al. Pulmonary alveolar microlithiasis: review and management. Current Opinion in Pulmonary Medicine 2009;15(5):486-90.

14. Samano MN, Waisberg DR, Canzian $M$, et al. Lung transplantation for pulmonary alveolar microlithiasis: a case report. Clinics (Sao Paulo) 2010;65(2):233-6.

15. Gocmen A, Toppare MF, Kiper N, et al. Treatment of pulmonary alveolar microlithiasis with a diphosphonatepreliminary results of a case. Respiration 1992; 59(4):250-2.

16. Ozcelik U, Yalcin E, Arıyurek M, et al. Long-term results of disodium etidronate treatment in pulmonary alveolar microlithiasis. Pediatric Pulmonology 2010;45(5):514-7.

17. Takahashi $H$, Chiba $H$, Shiratori $M$, et al. Elevated serum surfactant protein A and D in pulmonary alveolar microlithiasis. Respirology 2006;11(3):330-3.

18. Marchiori E, Franquet T, Gasparetto TD, et al. Consolidation with diffuse or focal high attenuation: computed tomography findings. Journal of Thoracic Imaging 2008;23(4):298-304. 